\title{
REALISATION, INSTANTIATION AND INDIVIDUATION: SOME THOUGHTS ON IDENTITY IN YOUTH JUSTICE CONFERENCING*
}

\author{
(Realização, instanciação e individuação: algumas \\ observações sobre reuniões por justiça)
}

\author{
J R MARTIN \\ (Department of Linguistics, University of Sydney)
}

ABSTRACT: This paper is concerned with identity and how it can be modelled in SFL, with special reference to the roles played by young offenders in Australia's youth justice conferences. These conferences function as a restorative justice alternative to courtroom-based retributive justice. It is proposed that a hierarchy of individuation be established, alongside and complementing realisation and instantiation, responsible for users of language, the ways in which semiotic resources are allocated to them, and the ways in which they use these resources to form social groups. This hierarchy is briefly explored in relation to teenage identity.

REsumo: Este trabalho se preocupa com identidade e como ela pode ser representada em LSF, com especial referência aos papeis desempenhados por infratores jovens em encontros da justiça juvenil da Austrália. Essas conferencias funcionam como justiça restauradora, alternativa à justiça retributiva das corte de justiça. Propõe-se que seja estabelecida uma hierarquia de individuação, ao lado e complementando as de realização $e$ instanciação, responsável pelos usuários da língua, a forma como recursos semióticos são a eles atribuídos e a forma como eles usam esses recursos para formar grupos sociais. Essa bierarquia é brevemente explorada em relação à identidade do adolescente.

Resumen: Este trabajo se relaciona con la identidad y con la manera en que puede ser representada en Lingüística Sistémico Funcional, con especial referencia a los roles desempeñados por infractores jóvenes en los encuentros realizados en el marco de la justicia juvenil de Australia. Estos encuentros funcionan como justicia restauradora, alternativa a la justicia retributiva de las cortes judiciales. Se propone que se establezca, junto y complementariamente a la realización y la instanciación, una jerarquía de individuación de los usuarios del lenguaje que responda por las maneras en que les son asignados los recursos semióticos y por las maneras en que ellos usan los recursos para formar grupos sociales. Esta jerarquía es brevemente explorada en relación con la identidad adolescente.

\footnotetext{
* The author acknowledges the support of the Australian Research Council for a Discovery Project grant supporting this restorative justice research.
}

D.E.L.T.A., 25:EspeCIAL, 2009 (549-583) 


\section{Teenage identity}

Recently I received the following e-mail from my son, who was representing the Australian family at a Canadian cousin's wedding:

$[1]$

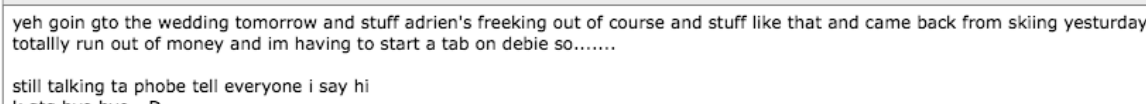

Writing informally to me, via this electronic medium, his text displays a range of features distinguishing it from the messages I was writing to him:

spelling (yeh, adrien, freeking, totallly, debie, ta, phobe)

punctuation (all lower case; no punctuation marks such as ,..:-')

acronym $(\mathrm{gtg}=$ 'got to go')

force (totallly)

commitment (and stuff, and stuff like that)

colloquial lexis (freeking out)

emoticon $(=D)$

Not surprisingly, distinctive features of 'textese' are evidenced (acronym, emoticon), as canvassed in Crystal 2006. And there are several markers as well of teenage talk (distinctive intensification, lack of commitment, colloquial lexis and so on), as outlined in Stenström et al. 2002, Stenström \& JØrgensen 2009. As Thurlow 2007 explores, language features of this kind are those which prompt media commentators to homogenise youth (this is how they all use language all the time), for bastardising English_(which is in moral danger), in ways no-one else can understand (to 'stylize' teenagers in Cameron's (e.g. 2002) sense of the term). It goes without saying of course that not all teenagers write like this, that my son doesn't write like this all the time, that English will survive and flourish however he talks, and that I can indeed understand what he is writing (excepting an unfamiliar acronym or two from time to time). Linguistics is at odds with popular culture in all these regards (and quite unlikely to sell as many newspapers if its voice were more clearly heard). 
From the perspective of social linguistics (Gee 1996, 2005), what is more interesting about this discourse is its function to "support human affiliation within cultures, social groups, and institutions" (Gee 2005: 1). If we put a constructivist spin on teenage talk, then what is distinctive about this talk is the way it construes teenage identity. As such it negotiates who belongs, and who doesn't, as the new-age Mum below, failing to relate to her son, laments:

[2] Status update: mum's on Facebook

The addictive social network is weaving its spell on parents - much to the chagrin of our kids.

Needless to say, neither of my kids would friend me.

Nick to Mum: "I'm not your friend. I'm your son, No way I'm friending you."

Mum to Nick: "Shouldn't it be 'befriend' instead of 'friend'? It's grammatically incorrect.'

Nick to Mum: "That's my point exactly. You are too old to be on Facebook."

Oh yeah? [Essential April 16, 2009 Sydney Morning Herald]

Generational exclusion of this kind, alongside the media styling noted above, has given rise to spoofs of teenage speak - some more critical than others. The most entertaining of these is almost certainly four-time National Poetry Slam champion Taylor Mali's 'Totally Like Whatever', available on Youtube. Typically these spoofs are overdetermined, hyperbolising the incidence of 'youngspeak' features in relation to their incidence in corpus based studies (e.g. Stenström et al. 2002).

\section{Teenage Identity in Youth Justice Conferencing}

The question of teenage identity has become an important issue for us in our work on restorative justice in relation to youth justice conferencing in Australia (Martin et al. 2007, 2009, in press, Zappavigna et al. 2008, 2009). As part of this research we are studying the ways in which adolescents charged with an offence behave in a macro-genre designed to reintegrate them into the community. A typical conference includes the stages listed below, and involves the Young Person (YP), and their support person (typically their mother), the Victim, and their support person, an arresting officer, a police Youth Liason Officer (YLO), and at times an Ethic Liason Officer (ELO) and Translator as appropriate; the conference is coordinated 
by a Convenor, who is a lay person especially trained for this process. The result of a successful conference may involve an agreed upon community service plan for the YP, which may be supervised by the attending YLO. Overall the conference has been designed as a restorative justice alternative to retributive justice - i.e. going to court and receiving punishment from a magistrate, possibly involving juvenile detention.

Gathering

Legal framing

Commissioned recount

Victim's rejoinder

Victim's supporter's recount

'Third party' recounts

Offender's supporter's recounts

Offender's rejoinder

Brokering an agreement

Break

Ratification of outcome plan

Formal closing

(Shared refreshments)

Dispersal

In our work on the Commissioned Recount genre in this macro-genre, which has the schematic structure (Orientation) $\wedge$ Record of events (Re-Orientation) $\wedge$ (Extension) $\wedge$ Interpretation ${ }^{\wedge}$ Ramifications, we found that the YP generally offered a relatively succinct retelling of the events of the offence, which often needed to be extended into a fuller account through questioning by the Convenor; in addition the YP generally provided very little evaluation of these events, except when prompted to do so by the Convenor. This type of minimalist response is exemplified below, for an offence involving a stolen mobile phone:

[3] Orientation

Yeah, I was, I was walking to a mate's house.

Record of events

This guy just came up to me 


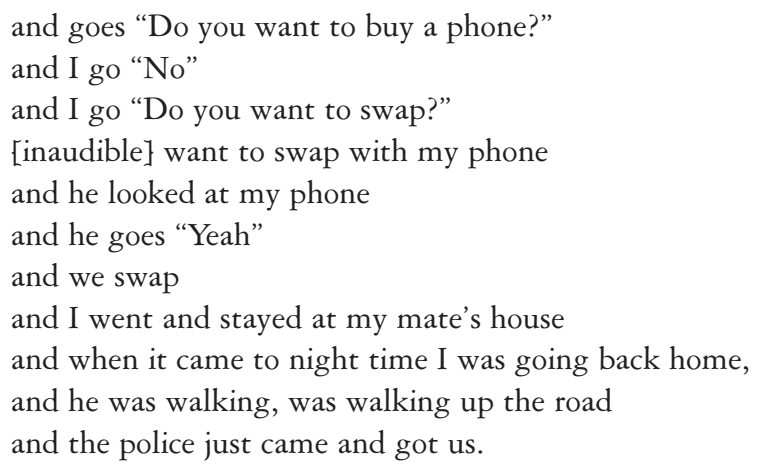

Re-orientation

That's it.

The Convenor then intervenes to add detail (Extension)...

[3'] [And then what happened? They came and got you. They found the phone. What did they say to you?]

- They go that this phone was stolen

[OK. What did you say?]

- I go, you know, I swapped it. Yeah, they just took took me.

[Took you where?]

- Police station

[OK. And who did they ring when they brought you to the police station?]

- My dad.

$\ldots$ and also to explore the emotional and ethical significance of events (Interpretation):

[3"] [And what did your dad say? Was he angry, happy?]

Angry.

[ Did you realise that this phone was stolen?]

[You did.]

[So why did you take it if you realised it was stolen? [pause]

[You need to tell us why you took the phone.]

Because it was new.

[Because it was new. Newer than yours. So you didn't care that it was somebody else's phone? Is that right?]

Yeah. 
[Did your father attend the police station?]

Yep

[And what did dad say when he got here?]

$\mathrm{He}$ (was) just asking why am I here?

And the police told him.

[And was he happy? Did he say anything to you?]

Don't go anywhere.

[As is when you get home you've got to stay home? Do you think your father was disappointed in you?]

Yep.

[So you know you did the wrong thing and did you know whose phone is was at that stage?]

Nah, when they told me () I asked (him) at school and then he goes "Yeah, it was my phone".

[Did you say anything to him when you found out that it was his phone?]

Nah.

[So you didn't say sorry to him?]

(Nah), I said sorry and he was about to say "So it wasn't you that did it".

For the remainder of the Convenor's negotiation of the significance of this offence (including more Interpretation plus Ramifications), see the Appendix.

As has already been reported in our publications, in the conferences we have considered to date, there is a highly visible regulative discourse, with the Convenor controlling the interaction. This is understandable since this is a legal process and an unfamiliar genre for several participants (the YP, Victim, and their supporters). Following on from this point, the Convenor initiates almost all exchanges with the YP, typically with questions. And interpretation of the recount is jointly constructed with the Convenor introducing virtually all evaluation (with respect to both emotion and values) and YP responding a word or phrase at a time.

Advocates of restorative justice ceremonies of this kind admit that conferences may well get off to a slow start, but suggest that they transform into a passion play of shame, remorse and forgiveness later on: 
... In a reintegrative family group conference... the initial response of the perpetrator is often indifferent and unconcerned... Yet as the conference runs on and both family groups began to speak about their estrangement from the perpetrator, that individual comes swiftly to learn that the love of the community is a deeply missed and quite important part of his or her world. With such recognition comes an avalanche of shame, after which the individual is likely to express remorse, accept the forgiveness of all concerned, and sign a document pledging to work in some way to repair or undo the damage produced by the antisocial act. [Nathanson 1997 The Annual of Psychoanalysis 25]

The Australian designers of the New South Wales Youth Justice Conferences we are considering make observations of a similar kind:

Braithwaite's predictions about the collective willingness to forgive but not forget, and about the collective concern to achieve social reintegration, were proving to be highly accurate. But neither he nor we could account for the emotional power of conferences. We could not well explain the regular tangible, visible progression through clearly marked stages of tension, anger, shame, remorse, apology, forgiveness, relief, and cooperation. [Moore \& O'Connell 1994]

In our observations and data analysis to date, however, we have found that interactions between the YP and other conference participants continue throughout the conference to unfold very much along the lines illustrated above. We have seen only glimpses of remorse and apology, and in most cases these had to be elicited by the Convenor or YLO/ELO involved. This is rather puzzling given the reported general satisfaction with these and related restorative justice procedures on the part of YP and Victims alike. Elsewhere we have explored this disjunction in relation to a Turner-inspired notion of 'ritualised redressive action' (Martin et al. 2009); my concern here is to focus on why the typical YP doesn't live up to designers' expectations, and how this impacts on the way we model users of language in systemic functional linguistic (SFL) research.

\section{Realisation, instantiation and individuation}

As is well known, SFL has had a long-standing concern with users and uses of language (Halliday et al 1964, Chapter 4). That said, the primary focus of its research effort over the past 6 decades has been on language systems, organised by strata, rank and metafunction on a hierarchy referred 
to as realisation (as schematised in Fig. 1 below). For state of the art perspectives on this trajectory see Halliday \& Webster 2009, Hasan et al. 2005, 2007, Matthiessen \& Halliday 2009 and Webster 2008. Exemplary work on English is consolidated in Halliday \& Greaves 2008 (phonology), Halliday \& Matthiessen 2004 (lexicogrammar) and Martin \& Rose 2007 (discourse semantics); for other languages see Caffarel et al. 2003.

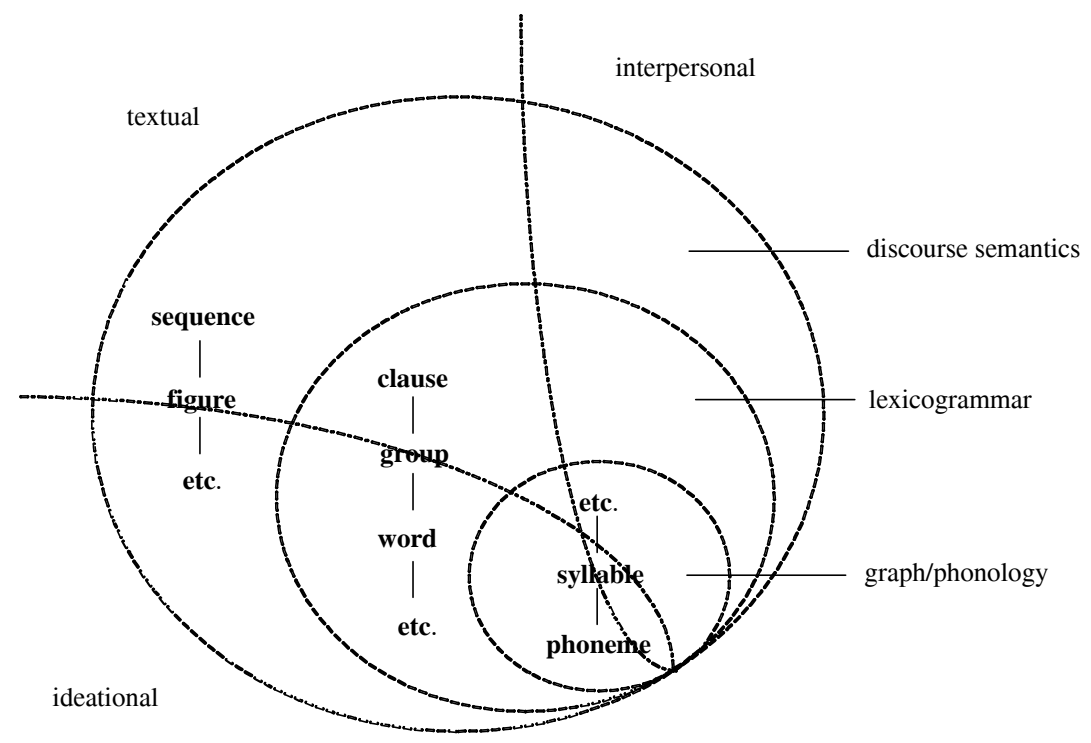

Figura 1: Realisation (strata, rank and metafunction).

For the most part SFL has brought users and uses of language into this picture by further stratifying language in relation to social context. This has meant adding on an additional stratum to model social context as field, tenor and mode (sometimes called register; e.g. Martin 1992), and for some systemicists (e.g. Martin \& Rose 2008) one more stratum to recontextualise these as genre (see Fig 2 below). In a realisation hierarchy of this kind, strata are related through metaredundancy - as patterns of patterns; the realisation hierarchy is thus formulated as a hierarchy of abstraction, beginning with phonological or graphological patterns and ultimately pushing through to genre. 


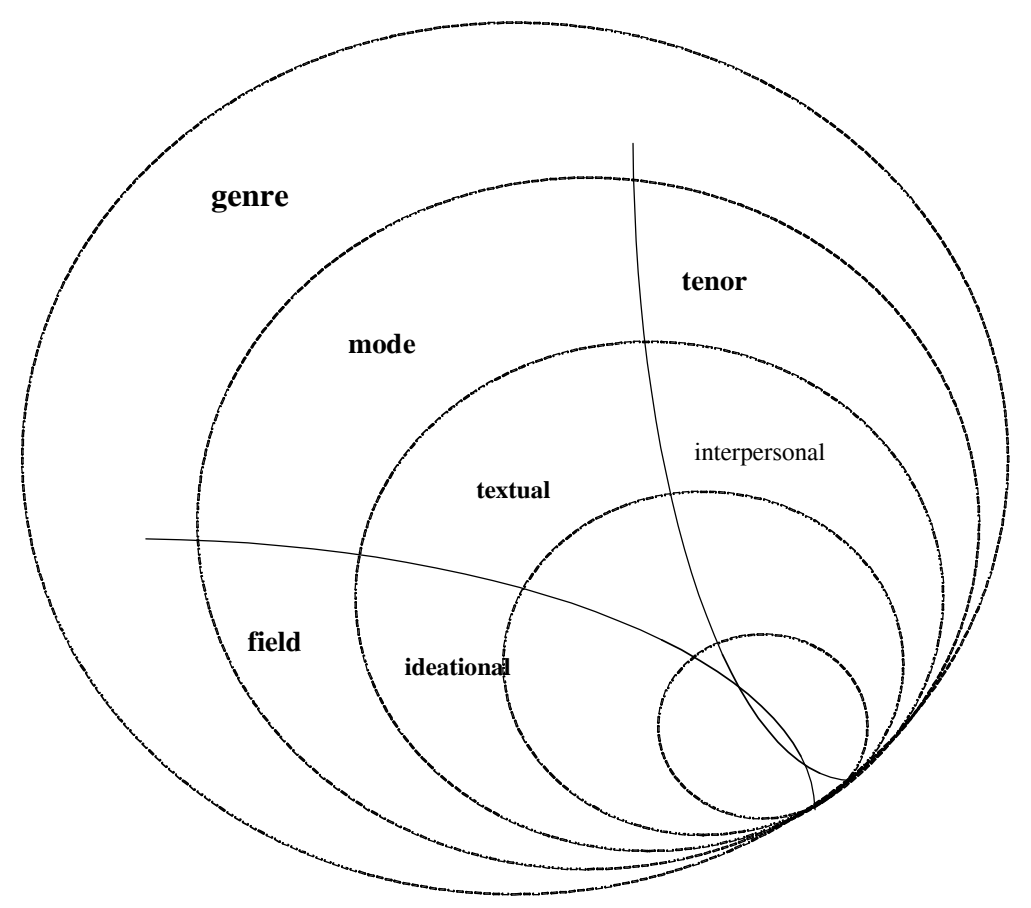

Figura 2: Realisation (language, register and genre).

This is not of course to argue that alternative perspectives on uses and users have not been proposed. Halliday (e.g. 2005: 254) regularly acknowledges the presence of an additional hierarchy oriented to language use, referred to as instantiation (see Table 1 below). His cline of instantiation has language and cultural systems at one end, generalising long term patterns, and texts in particular situations at the other, specifying instances of language use; in between he places his notions of register/text type for language and institution/situation type for context. Be that as it may, SFL contributions to the vertical axis (realisation), along the system column of instantiation far and away outstrip contributions to the horizontal axis, along the sub-system/instance type column. Numerous descriptions of specific instances of use have of course been published, but these have by and large not been generalised up the instantiation cline - primarily because of the difficulty of computing meaning and the time consuming task of manual analysis given the rich realisation apparatus discussed above. 


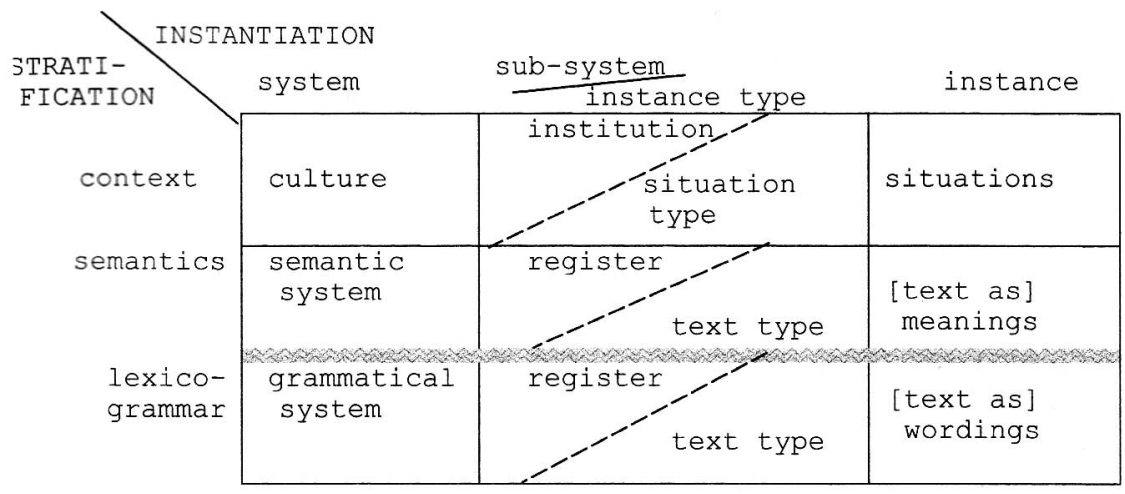

Table 1: Halliday's instantiation/stratification matrix.

Martin (e.g. 2006, 2008a, b, 2009) elaborates the instantiation hierarchy by adding genre/register and text type as stepped degrees of generality on the ladder, and adding reading as a sub-potentialisation of text to allow for different users' uptake of meaning in socially subjective ways (Fig. 3 below). Compared with realisation, which is a hierarchy of abstraction, instantiation is thus a hierarchy of generalisation. It is this difference that lies behind the different position of genre on the two hierarchies. As a recurrent configuration of field, mode and tenor patterns, genre sits on top the realisation hierarchy, as the highest level pattern of patterns. But since each genre constitutes a subpotential of the meaning potential of the system as a whole, it sits one rung down on the instantiation hierarchy, on the way from system to reading. Genre and register are positioned at the same level of generality in Fig. 3 because they constitute the same degree of sub-potentialisation (since genre coordinates and phases relationships among a culture's recurrent field, tenor and mode configurations as unfolding discourse; Martin 1999, 2001).

It is also important to remind ourselves here, by way of appreciating the complementarity of realisation and instantiation, that all strata along the realisation hierarchy instantiate (Fig. 4 below). Moving down through realisation from genre to graphology/phonology in other words brings us no closer to an instance of language use, since realisation is concerned with modeling patterns (of patterns) at the system end of the instantiation cline. 


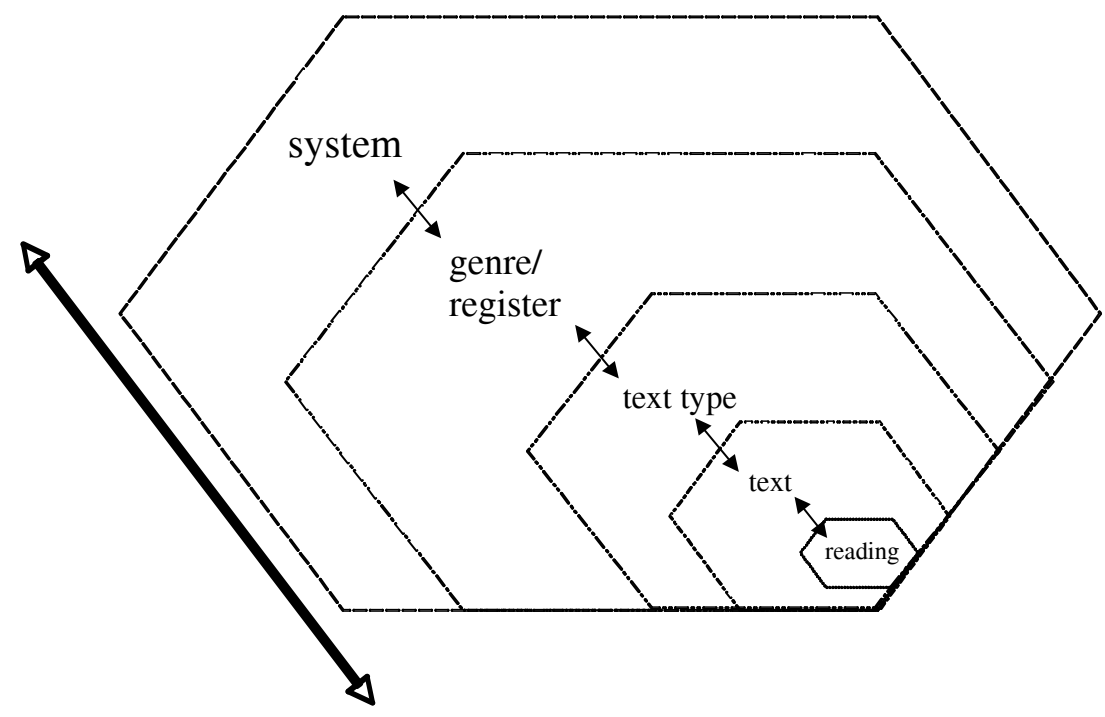

Figura 3: Instantiation as a hierarchy of generalisation.

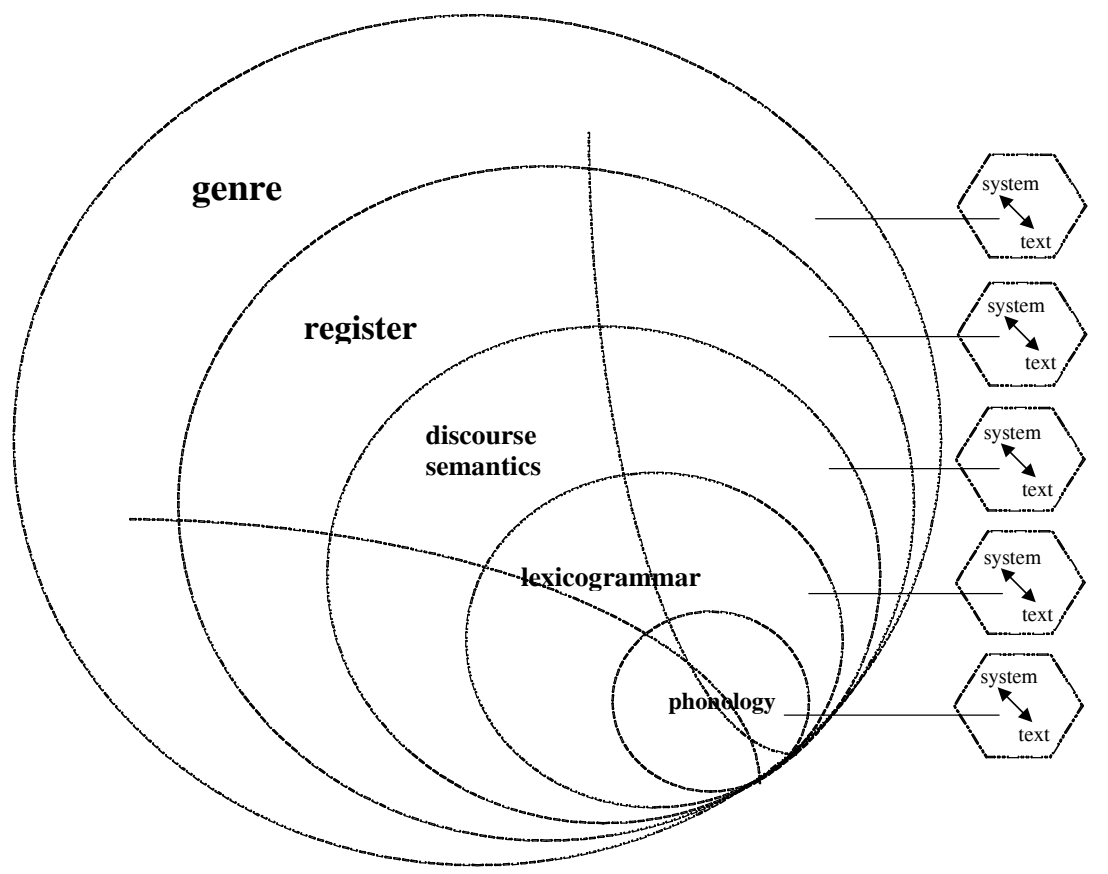

Figura 4: Realisation in relation to instantiation (all strata instantiate!). 
As far as instantiation is concerned, the commissioned recount presented above (text 3), exemplifies one recurrent subpotentialisation of the linguistic meaning potential of our culture. We can map its relation to agnate subpotentialisations typologically as in Fig. 5, treating it as a member of the story family, unfolding chronologically (time structured), unproblematically (expectant), with evaluation as a final stage (culminative interpretation). This shows how the genre is categorically similar to and different from other story genres in the network - i.e. for this account, personal recount, anecdote, exemplum, narrative (Martin \& Rose 2008). An alternative topological perspective is presented in Fig. 6, focussing on the nature of story genre evaluation. The axes configuring semantic space here are: i. a vertical cline scaling stories according to whether their evaluation tends to be culminative, after the events of the story have been told, or prosodic, accompanying their unfolding, and ii. a horizontal axis scaling stories according to whether their evaluation tends to be inscribed by the narrator or prescribed by a 'narratee' - e.g. a restorative justice

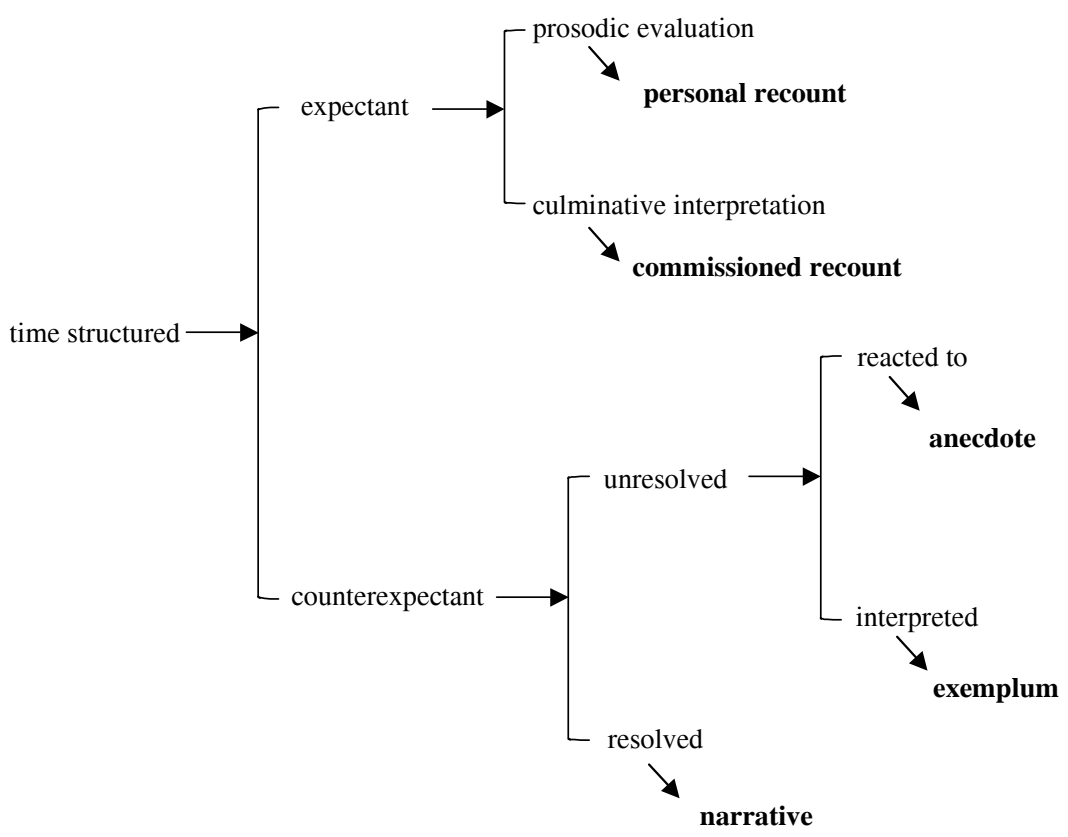

Figura 5: A typological perspective on story genres. 
Convenor (in commissioned recounts) or literacy critic (for thematic narratives ${ }^{1}$ ). For further discussion of commissioned recounts as a kind of story genre see Martin et al. 2007.

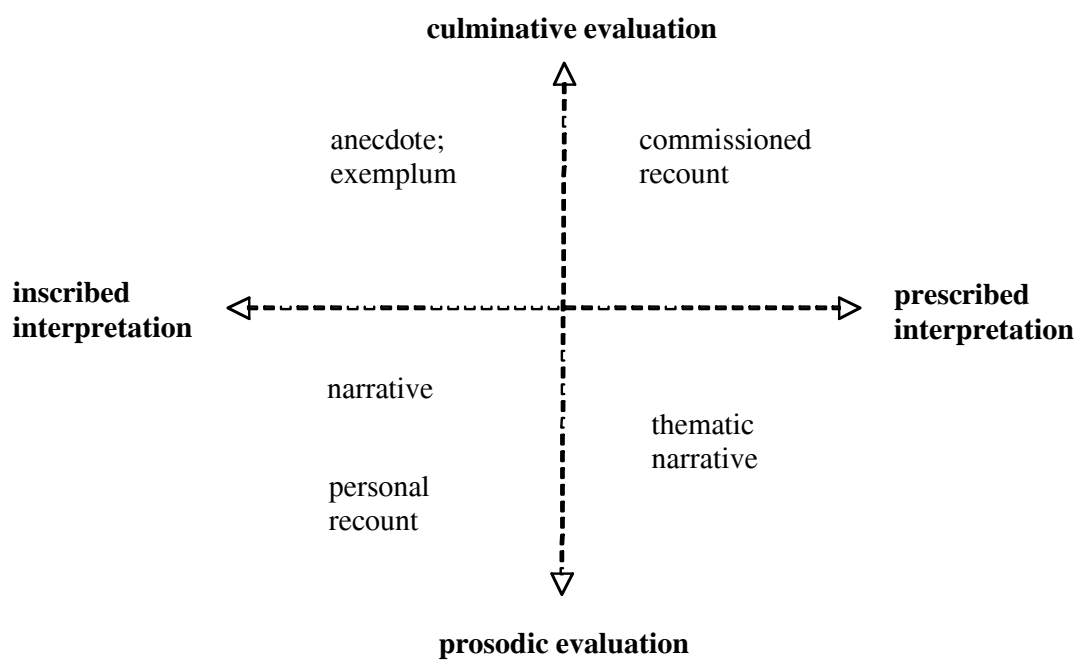

Figura 6: A topological perspective on story genres.

Pushing down the instantiation cline, Zappavigna at al. 2008 suggest that some commissioned recounts feature a rhetoric of tempered admission involving a range of 'mitigating' linguistic features. For example, graduation (Martin \& White 2005) is used to tone down force and focus, reducing intensity and quantity, and blurring the boundedness of entities and processes. So although a YP has admitted to the facts of their case, they may wish to downgrade the scope of their intentions and actions as minimal, within the constraints that those facts impose. In addition, opposing voices were distanced using engagement (Martin \& White 2005); for example, YPs attempt to close down voices that have the potential to scale up the graduation. Tempering of ideational meaning by the YPs also typically ${ }^{1}$ Thematic narratives are highly valued literary narratives which symbolise an 'underlying' moral
or 'theme' in Hasan's 1985 sense of the term; see also Martin \& Rose 2008. 
involves some undercommitment (Martin 2008a) as far as specificities of behaviour and phenomena such as the physical layout of the crime scene were concerned; for example, a YP might minimise the frequency with which they located themselves as the agent responsible for an offending material process. This swarm of tempering features is summarised in Fig. 7 ; text 4 exemplifies contracted engagement (concessive just), soft focus ( $a$ bit (open\}, \{walking\} around, seemed ${ }^{2}$ (to be\}, started (running)), agentless passive (one wall...kept getting damaged) and undercommitment (same sort of thing).

[4] Convenor: And A, what about you, what happened for you on that day?

YP: Same sort of thing, we were just walking around and walked up the path that the house was on and the door was just a bit open, we went in there. It was all dark and the windows were boarded up and so there was a few holes in the walls. We just started running around the place, punching and kicking holes in the walls ...there's one wall that just kept getting damaged. We just seemed to be getting more into it as it went on ... and then before we knew it the police had arrived out the front. We tried to get out but we couldn't.

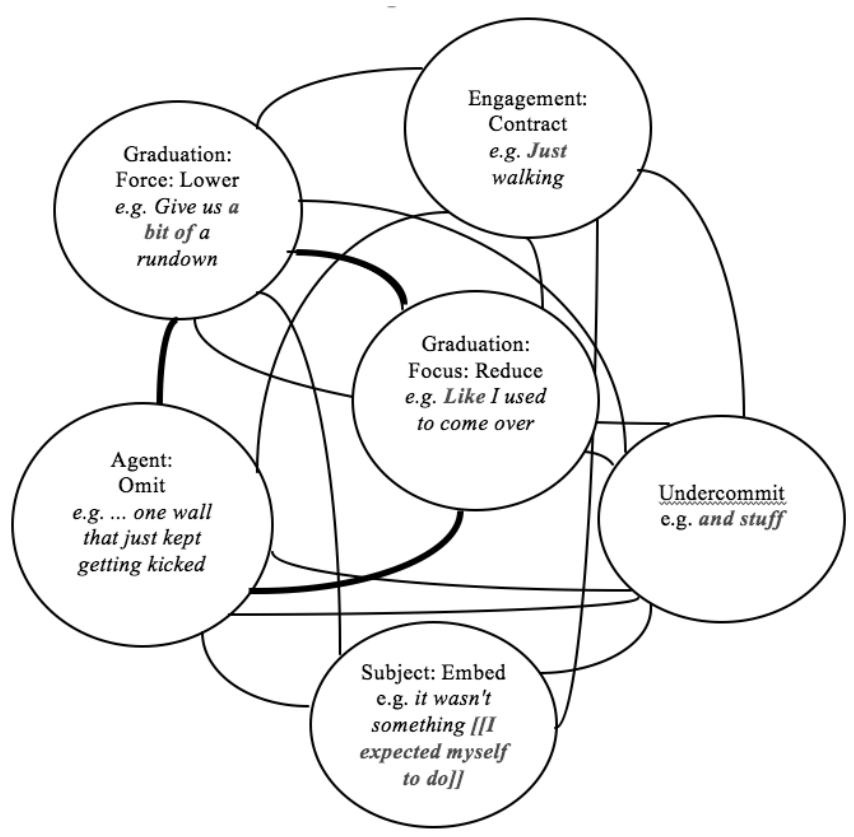

Figura 7: Small target resources deployed by YP (after Zappavigna et al. 2008).

\footnotetext{
${ }^{2}$ For soft focus graduation options (realised by seemed, started in text 4) in relation to processes see Hood in press.
} 
From the perspective of instantiation we can treat this 'small target' testimony as a sub-type of commissioned recount - a tempered commissioned recount if you will. But however far we push this kind of specification, we would not arrive at an account of the kind of user predisposed to realise a commissioned recount in such a way. For this kind of account we have to switch focus, from uses to users of language, and think about the specification of meaning potential in a culture in terms of individuation - a third complementary hierarchy, alongside realisation and instantiation.

To date, SFL researchers have explored two complementary ways of thinking about individuation. One, inspired by Hasan's work on semantic variation (Hasan 2005a, 2009, Williams 2005), interprets individuation as a hierarchy of allocation whereby semiotic resources are differentially distributed amongst users - both in terms of which options are available and of those available, which are likely to be taken up in specific contexts of instantiation. Bernstein uses the metaphor of reservoir and repertoire to describe the semiotic affordances of users in relation to their communities as a whole along these lines:

I shall use the term repertoire to refer to the set of strategies and their analogic potential possessed by any one individual and the term reservoir to refer to the total of sets and its potential of the community as a whole. Thus the repertoire of each member of the community will have both a common nucleus but there will be differences between the repertoires. There will be differences between the repertoires because of the differences between members arising out of differences in members context and activities and their associated issues. [Bernstein 2000: 157]

One thing we have to guard against here as functional linguists is a neuro/biological interpretation of individuals and communities instead of a social semiotic one. As Firth warns, it is not psycho-biological entities we are exploring, but rather the bundles of personae embodied in such entities and how these personae engender speech fellowships. We're not, in other words, looking at individuals interacting in groups but rather at persons and personalities communing in discourse.

The unique object of Saussurian linguistics is 'la langue', which exists only in the collectivité. Now at this point I wish to stress the importance of the study of persons, even one at a time, and of introducing the notions of personality and language as in some sense vectors of the continuity of repetitions in the social process, and the persistence of personal forces." [Firth 1957a: 183] 
“... if we take a sociological view of the personae or parts we are called upon to play in the routine of life. Every social person is a bundle of personae, a bundle of parts, each part having its lines. If you do not know your lines, you are no use in the play. It is very good for you and society if you are cast for your parts and remember your lines." [Firth 1957a:184]

"A speech fellowship sees itself and hears itself as different from those who do not belong. Such speech, besides being a bond among fellows, is a bar to the outsider... within such speech fellowships a speaker is phonetically and verbally content because when he speaks to one of his fellows he is also speaking to himself." [Firth 1957a: 186]

"My intention is to link language studies with social human nature, to think of persons rather than individuals. Linguistics may learn something from the sciences which treat human beings as separate natural entities in their psycho-biological characters, but it is mainly interested in persons and personalities as active participators in the creation and maintenance of cultural values, among which languages are its main concern." [Firth 1957a: 186]

This brings us to a second, complementary perspective on individuation which at how personae mobilise social semiotic resources to affiliate with one another - how they share attitude and ideation couplings ${ }^{3}$, in Knight's 2009 terms, to form bonds, and how these bonds then cluster as belongings of different orders (including relatively 'local' familial, collegial, professional and leisure/recreational affiliations and more 'general' fellowships reflecting 'master identities' including social class, gender, generation, ethnicity, and dis/ability). As with realisation and instantiation, it is difficult to find a neutral term which privileges neither a top-down nor a bottom-up perspective. We'll adopt the term individuation for this hierarchy here, keeping in mind that it is concerned with both how semiotic resources are distributed among users (allocation) and how these resources are deployed to commune (affiliation). An outline of this user oriented hierarchy is presented as Fig. 8.

The different orientations to meaning implicated by an individuation perspective on semantic variation have repercussions for instantiation, since they condition both recognition and realization rules (Bernstein 2000: 104f). Recognition rules allow speakers to identify the specificity or similarity of contexts, and thus orient to what is expected or legitimate in that context;

\footnotetext{
${ }^{3}$ For notes on coupling in relation to instantiation see Martin 2008a, 2009.
} 
realization rules enable speakers to produce culturally specific texts and practices. As Bernstein comments '...one may be able to recognise that one is in a sociology class but not able to produce the texts and contextspecific practices. In order to produce the legitimate text it is necessary to acquire the realisation rule' (2000: 105).

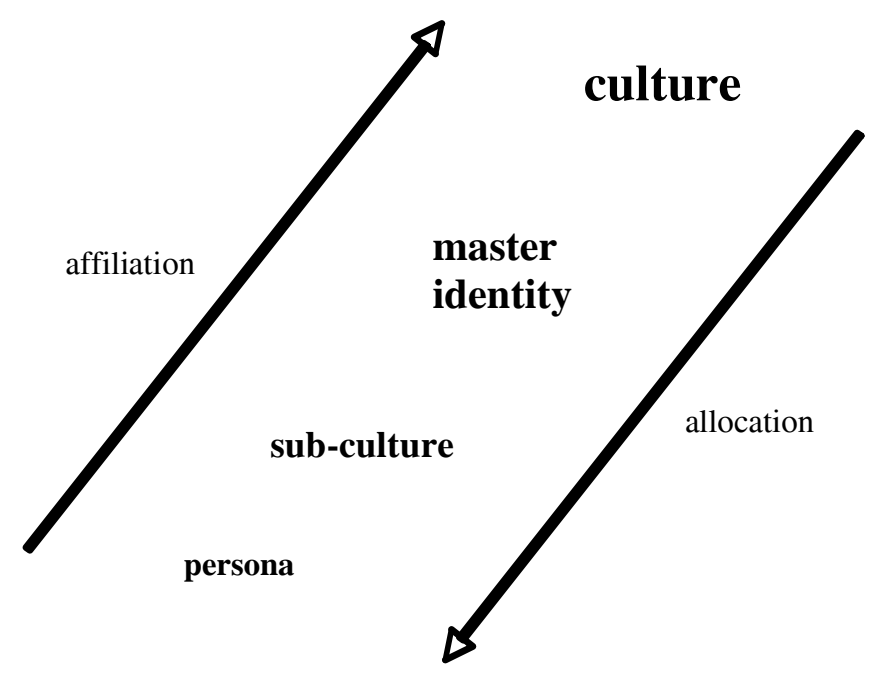

Figura 8: Individuation as a hierarchy of affiliation and allocation.

As with instantiation, we need to keep in mind that as far as realisation is concerned, all strata individuate (Fig. 9 below). As Firth 1957b: 191192 , once quipped in relation to phonology and accent, 'It is part of the meaning of an American to sound like one'), and similarly so for every higher level of language and social context - i.e. lexicogrammar, discourse semantics, register and genre. Taking all three herarchies into account is a challenging task; but we always already individuate as we instantiate as we re/deploy the realisation resources of our culture (apologies to Derrida).

And bringing time into the picture, our culture always already evolves (phylogenesis) as we develop as individuals (ontogenesis) as texts unfold (logogenesis). 


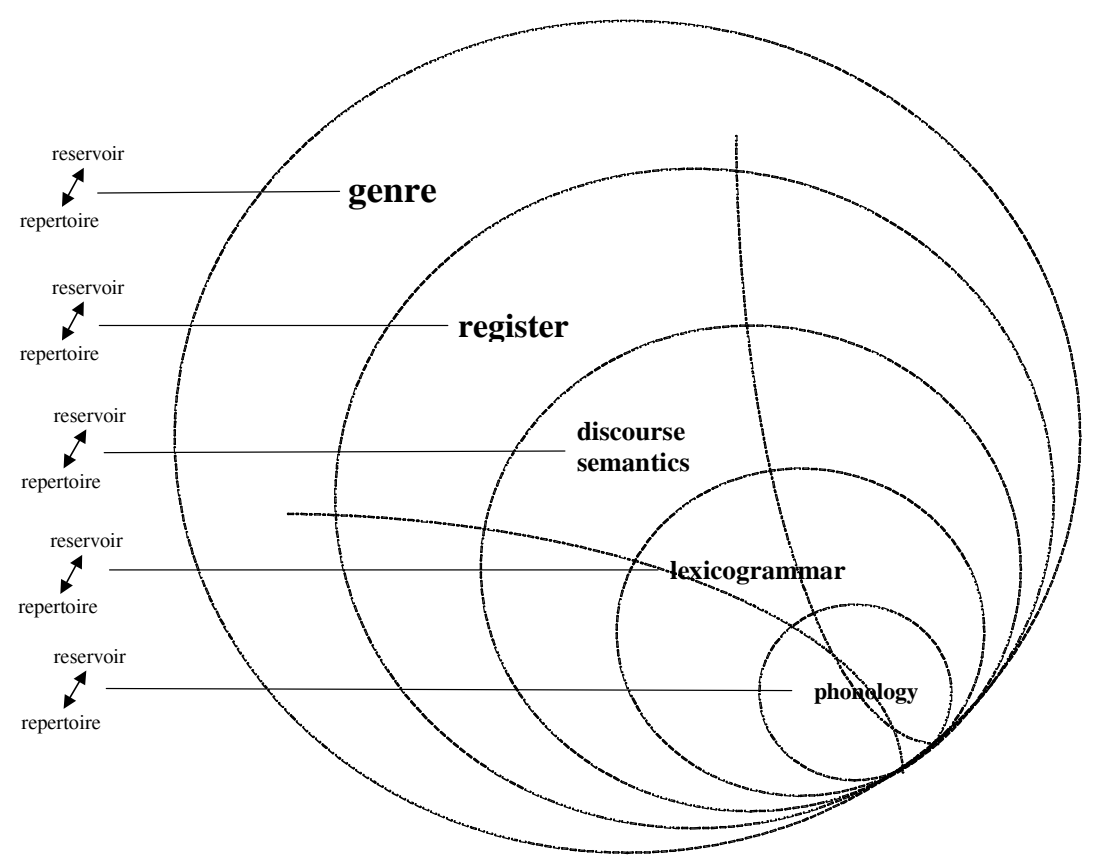

Figura 9: Realisation in relation to individuation (all strata individuate!).

\section{Adolescent identity in youth justice conferencing}

The point of developing this discussion of individuation in relation to instantiation and realisation has been to open up discussion of the way YPs are positioned in youth justice conferences and how they play their role. Text 3 and its extensions (3', 3', Appendix) illustrate a canonical 'small target' response. The Convenor has to do a lot of work extending the recount, and extracting evaluation. Text 5 below illustrates a more forthcoming testimony.

[5] YP: Well um I was just staying at [suburb], staying at a friend's place, [name], and um, and her mum's and she had her own flatmates so I... (and mum had her own) and I was staying at theirs ( $)^{4}$ so I could get back ( ). And um, well, we had ( ), y'know, we was just sitting around, chuffing on so um... we just started taking

\footnotetext{
${ }^{4}$ ( ) encloses doubtful transcriptions or uninterpretable sections of the recount.
} 
drugs and um (mainly we) um, got some, um, acid trips. And we got on top of some, yeah. I was under the influence of drugs at the time. We were just walking around ( ) with nothing else to do and (saw some) shops down the road so (I had, sort of like) had the munchies so I started to go down the road, and um, steal a packet of chips and yeah. Well first, we stood out the front, like y'know, really suss, and talkin' about it and then we all walked into the store and stood around and (just laughing and) next thing you know, sort of like, walked down there and went (out) and back up to the front and um, and then ( ) yeah, went back in and grabbed a bag of chips and then we started running down the road and we came across one of the other people (that were) at the shop, so we kept running (to about) down to the train station, and we already gone to [place] to come back at that time and um, we were sitting at the train station back down [place] and um well I was sittin' there ( ) in my hand and chips in the other and um, yeah I was (saw) the copper walkin' down and um... well I, I freaked out and thought 'oh shit (I should) run'. And um so (he made [name of friend]) sitting next to me, she told me to sit down and I said no it's like ( ) (I'm not getting caught on somethin'). So I started running down the tracks and um, threw my chips at the train, started running, and then, like, got down to the bridge and I watched the copper, [name] and that walk up to the thing (sort of ( ) what he was saying to me ) and um as I was climbing up ( ) just leave the train station and then I ran all the way, like, back up to the flats I was staying at. And, yeah, went back up to the flats and I was sitting inside (with the mum) and just asked her not to tell the copper I was there but the coppers knocked on the door, and ( ). Knocked on the door and um, asked if I was there and [name]'s gone yeah and plus I left the door at the back ( ) so she had to go out anyway, so I just walked out anyway and stood up (near the stairs) and one of the officers told me not to run, so the (first thing I did) was run ( ) down the road and then finally one of the (young) officers got me just down the road and um, yeah. He got me and I just kept, y'know, swearing at him and just wouldn't stay still and um yeah I got taken back to the cop station and then, taken to the hospital. ( ) That's what happened.

The same YP is also requires much less promoting as far as evaluation is concerned, and commits her own self-criticism, remorse and apology:

[6] Convenor: So what have you thought about since, um, since this incident? ( YP: How stupid I was. I was just, y'know, I dunno, I was just stupid, I think, at that time. I'll think twice next time (before I do something like that again).

[7] Convenor: So how long after the incident did you have a chance to sort of reflect back on it and think about what happened.

YP: Pretty much that day (I called home and I was describing to my mum) that doing that stupid incident that night because that day I (wanted to) go back and apologise cause ( ) I always go there and I felt so bad cause um, they're always nice to us and we went and done stupid things ( ). Yeah, I was stupid. 
In fact this YP comes far closer to the ideal proposed by designers and advocates of restorative justice conferencing than other YPs in our study. She both recognises and realises the role she was intended to play, in stark contrast to the YP in text 3 above, who in Firth's terms was apparently poorly cast for his part and did not know his lines.

This raises the question of how we model users of language in relation to individuation. Hasan and her colleagues (see references in Hasan 2009, Williams 2005) approached this from the perspective of factor analysis, foregrounding syndromes of semantic features constituting divergent orientations to meaning in critical socialising contexts as far as gender and social class are concerned. We have not attempted a comparable quantitiative analysis of semantic variation in our own research. We have however drawn on the work of Maton (2000, 2007, 2009; and Moore \& Maton, 2001), his Legitimation Code Theory in particular. Like Bernstein, Maton is a sociologist of education; he extends Bernstein's late work on knowledge structure (Bernstein 2000, Christie \& Martin) by focusing on knowers. Of special relevance here is his work on Specialisation or what makes someone or something different, special and worthy of distinction. This highlights that every practice, belief or knowledge claim is about or oriented towards something and by someone, and so sets up epistemic and social relations. Epistemic relations (ER) have to do with relations between educational knowledge and its proclaimed object of study (school physics and the material world for example); social relations (SR) have to do with relations between educational knowledge and the 'subject' (the author or actor making the knowledge claims). Each relation may be more strongly $(+)$ or weakly (-) emphasised in practices and beliefs, along continua of strengths, and these two strengths together give the legitimation code of specialisation (ER+/-, $\mathrm{SR}+/-$ ), as set out in Fig. 10. This gives four principal codes: for the knowledge code it matters more what you know and how, and less who you are (e.g. anyone can learn chemistry); for the knower code less what you know and how, more who you are (e.g. you need the right 'cultivated gaze' to do literary criticism); for the relativist code, neither what you know nor who you are is emphasised (everyone's perspective is equally valuable); and for the elite code it matters both what you know and who you are (e.g. Darwin, the wealthy gentleman biologist of 19th century England). 


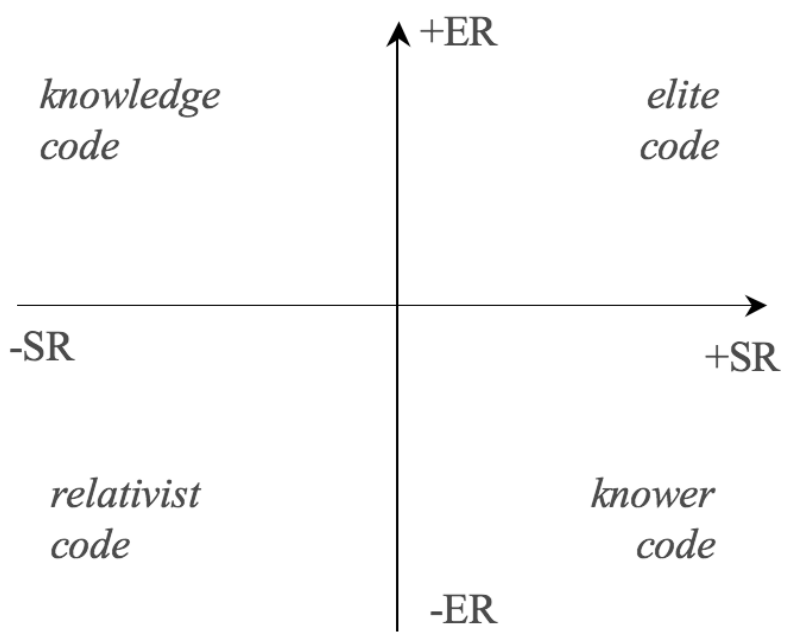

Figura 10: Maton's legitimation codes of specialisation (weaker/stronger epistemic/social relations).

As we have argued elsewhere (Martin et al. 2009), youth justice conferences can be treated as a kind of pedagogic discourse, with a regulative discourse projecting an instructional one. They are designed in other words to 'educate' YPs by repositioning them in relation to the offence committed and their future behaviour. If we consider Maton's concepts as capable of modelling different 'knower' roles in education, it seems possible to think about YP roles in conferencing in similar terms. Maton's epistemic relation would here refer to the relation between the YP's recount to what actually went on as far as the offence is concerned (how forthcoming or not); here we are concerned with the specificity of the YP's commitment of ideational meaning in relation to how much the Convenor wants replayed. Maton's social relation would here refer to the relation of the YP to that offence (how remorseful or not); critical here is the YP's axiological orientation to what $\mathrm{s} /$ he has done wrong.

Working along these lines, as outlined in Fig. 11 below, we can set up a vertical axis oriented to how forthcoming the YP is (a stronger to weaker epistemic relation of admission), and a horizontal axis oriented to how 
remorseful the YP is (a stronger to weaker social relation of contrition). Glossing this topology in relation to canonical positions, we can then recognise four possible identities for YPs: redeemed (forthcoming and remorseful), accused (neither forthcoming nor remorseful), guilty (forthcoming but not remorseful) and prodigal (unforthcoming but remorseful). In an identity topology of this kind, the 'compliant' YP from texts 5-7 (the train tracks affair) would be positioned as redeemed, whereas the 'resistant' YP from text 3 (the stolen mobile phone) stands accused.

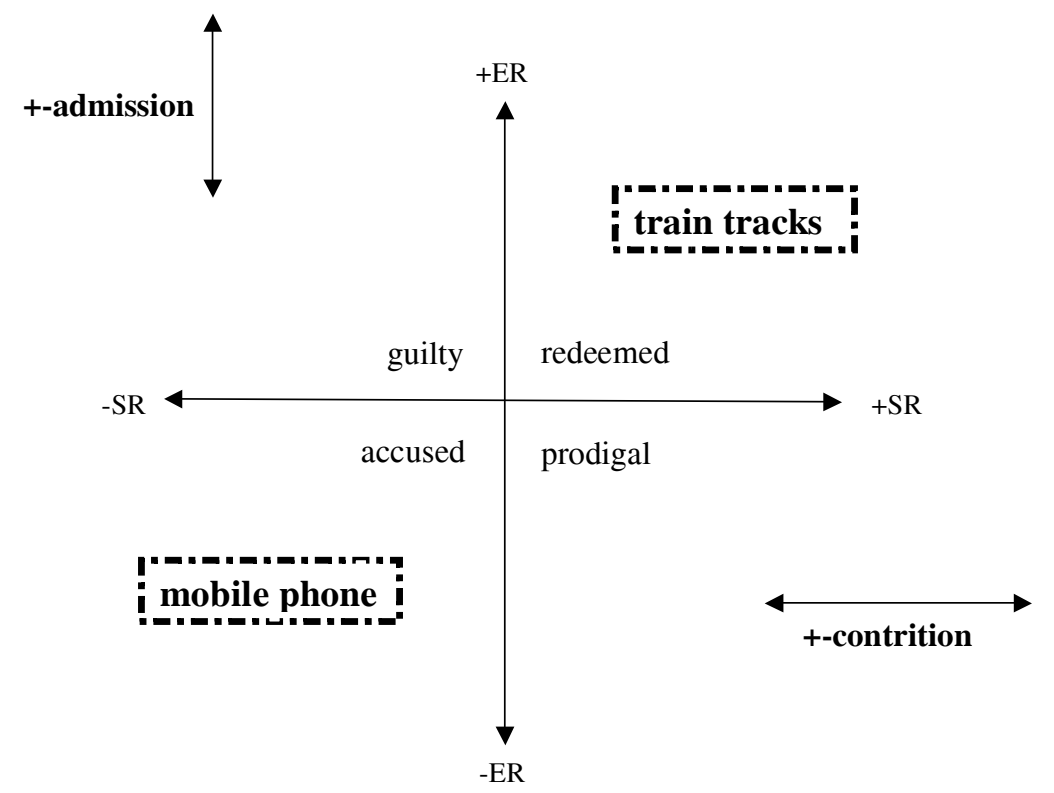

Figura 11: Specialisation of YP identity in youth justice conferencing.

Of course using the terms 'compliant' and 'resistant' to characterise the reading position instantiated by these two YPs is axiologically subjective, since it reads their behaviour from the perspective of the designers of youth justice conferencing. It is probably the case the YP in text 3 is cooperating as fully as his repertoire allows, given that this is in all probability the first time he has encountered the genre. What in his experience could he relate this genre to understand what is expected of him? A dressing down by a 
teacher or parent perhaps? A police caution? Counselling from a youth worker or school psychologist? And even if he can recognise what is expected, does he have the coding orientation to play the role? What would count as sincerity in any case, given adult expectations about how adolescents talk?

To problematise this further, let's consider two further personae. The first represents the guilty identity introduced above. His recount is relatively forthcoming; but it takes the Convenor and Ethnic Liason Officer a very long time to extract anything resembling remorse (as discussed in Martin et al. in press). In presenting these recounts we'll also be considering them from the perspective of teenage talk introduced in section 1 above, concentrating first on the following tempering features:

- soften focus (like; kind of, sort of)

- undercommitted 'discourse extension' (like, and stuff, or anything)

- minimising just

- intensifying/precipitating just

As can be seen below, this YP makes no attempt to minimise his involvement in what went on with mitigating resources of this kind:

[8] YP It was up there- It was- [inaudible] on a Tuesday yeah. [inaudible] and I got a call from my friend, Victor, [inaudible] to come down to Punchbowl. Something going on but when I went down with them to Liverpool station and jumped on the train [inaudible] and the train we got it straight to Punchbowl, we got off at Punchbowl [inaudible] Mxxxx and other- his other two friends. And they had a one-onone and I jumped in and I turn around. I was having a go with his friends and the [one] next to me got stabbed and he [inaudible] goes "Chase him!" and I went chased him, started chucking stuff at him, hitting him. I couldn't stop him. He still had the knife in his hand and after that I walked back to the station to see Vxxxx and I see the policeman coming as I walked away and [inaudible] happened to him and I said to the two officers assault me, search me, took out all my stuff and they found out I was involved and they took me back to the police station. And my [inaudible] and I had an interview and they took my pants, my hat, my jacket and I was released.

This contrasts with the swarm of tempering features in text 9 (in bold below). 
[9] [inaudible] and so, so it's a Sunday night and me, me and T were out and just, you know, hanging around and mucking about [inaudible] We'd run out of cigs so we just kind of, we just kind of [inaudible] went to the servo and stuff and, and [inaudible] the car door was open and the key was in the ignition and my mate was like "Yeah, do you want- Yeah, we should jump in the car and, you know, and jump in and kind of-" and I was like "Oh, I think, you know, are you sure about it?" And so he, then we kind of, we kind of, yeah, we just jumped in it and- I was in it for a while and, and, and then, you know, then he starts screaming at me, you know, "Shit, she's coming!" You know, "Just burn it, burn it mate! Go, just get out!" And so I kind of shut the door and don't think, and I'm just out of there, you know, just round the corner and then kind of on the road and stuff and then I realized like "Oh shit, I've taken the car" and then we, and then we kind of feel like "Oh OK, we can't do much now". So we kind of drive around for a while. We didn't fang it or anything and, you know, we each had a go and yeah, then, a bit later, after we kind of drove around for a while, yeah, I kind of took a corner too, too, sort of quickly and, and just sort of, you know, didn't- before I knew it, I was just [inaudible] and [inaudible] in Mr H's umm front yard and in his fence and, and then again, you know, just, I just didn't know what was going on and just shit-bolted out of there and $[\ldots .$.$] you know, and I was a bit, kind of, weirded out, like, so I was just$ kind of, kind of, just sitting at the bus stop and stuff [inaudible] till the cops came and saw us. Yeah, they just came and got us.

Of equal interest is the slang, swearing and colloquial lexis ('slanguage' in Stenström et al.'s terms), which young people use in more casual settings to bond with one another (bold below). In the analysis below we've also included related dialogic features like you know, OK, yeab (bold underlined below) which explicitly engage an audience. Text 8 features some of these:

\author{
It was- [inaudible] on a Tuesday yeah \\ they had a one-on-one \\ I was having a go with his friends \\ he ... goes 'Chase him!" \\ I went chased him, \\ started chucking stuff at him
}

But text 9 uses many more, including some colloquial grammar (case me and T; 'historical present' tense - he starts screaming, we...drive around a bit).

[inaudible] and so, so it's a Sunday night and me, me and T were out and just, you know, hanging around and mucking about [inaudible] We'd run out of cigs so we just kind of, we just kind of [inaudible] went to the servo and stuff and, and [inaudible] the car door was open and the key was in the ignition and my mate was 
like "Yeah, do you want- Yeah, we should jump in the car and, you know, and jump in and kind of-" and I was like "Oh, I think, you know, are you sure about it?" And so he, then we kind of, we kind of, yeah, we just jumped in it and- I was in it for a while and, and, and then, you know, then he starts screaming at me, you know, "Shit, she's coming!" You know, "Just burn it, burn it mate! Go, just get out!" And so I kind of shut the door and don't think, and I'm just out of there, you know, just round the corner and then kind of on the road and stuff and then I realized like "Oh shit, I've taken the car" and then we, and then we kind of feel like "Oh OK, we can't do much now". So we kind of drive around for a while. We didn't fang it or anything and, you know, we each had a go and yeah, then, a bit later, after we kind of drove around for a while, yeah, I kind of took a corner too, too, sort of quickly and, and just sort of, you know, didn't- before I knew it, I was just [inaudible] and [inaudible] in $\mathrm{Mr}$ H's umm front yard and in his fence and, and then again, you know, just, I just didn't know what was going on and just shitbolted out of there and [...] you know, and I was a bit, kind of, weirded out, like, so I was just kind of, kind of, just sitting at the bus stop and stuff [inaudible] till the cops came and saw us. Yeah, they just came and got us.

Tellingly, the speaker of text 9 is not a YP, but rather a middle aged professional actor and research student playing a YP in a mock conference staged in the Department of Performance Studies at the University of Sydney as part of our preparation for recording and observing conferences. As with the Taylor Mali spoof noted in section 1, for adults, imitating teenagers seems to involve overplaying indexical markers, constructing a kind of hyper-identity; and given that fact that all the YPs we have observed adjusted their language to the relatively formal register of youth justice conferencing, this actor's construal of teenage identity in this context verges on caricature. Be that as it may, what this underscores is the kind of persona adults perceive teenagers to be, highly stylised in the ways Thurlow 2007 has documented. How can a teenage sound sincere and be themselves in conferences if these are the expectations adults bring? And sincerity, realising a strong social relation (Fig. 11 above), is an issue for Convenors, YLOs and ELOs as the following exasperated exchange with the YP from text 8 above illustrates:

\section{Convenor}

So do you think that this whole process is a waste of time? Do you really really care about what comes out of this? Seriously, honestly.

\section{Young Person}

Yeah, I do. 


\section{Convenor}

Ah, no, honestly? You can say it.

Young Person

No. I do.

Arresting Officer

Be upfront, man.

Youth Liaison Officer

Be honest. OK. Because it's no use sitting here saying, "I'm gonna change, blah, blah ,blah, lies, oh, I'm not really saying what I'm thinking" because I know this isn't you. OK. Because I've spoken to you before. If someone had a go at you like this, just react how you would normally. Say what you think.

As we can see, the youth justice conferencing genre is a potentially challenging one for teenagers. The adults involved are hoping for a sincerely remorseful and apologetic persona which they can help re-integrate into the community. But the social relations are such that most YPs adopt a small target stance and can't really be themselves (or at least not the selves that adults might expect them to be based on stylised preconceptions of their behaviour in social process of other kinds). Zappavigna et al. 2008 go so far as to suggest that a middle class coding orientation might be required for YPs function compliantly in this genre, where they must almost instantaneously recognise the role they are meant to play and quickly access the realisation rules they need to play their part. Typical offenders of course have a rather different semiotic repertoire, with master identities of social class and ethnicity affording much less compliant reading positions.

\section{Users and uses of language in $\mathrm{SFL}^{5}$}

This paper has focused on the importance of recognising users of language alongside uses in SFL, with reference to the issue of teenage identity in youth justice conferencing. Users have not of course been totally

\footnotetext{
5 My thanks to my co-researchers Michele Zappvigna and Paul Dwyer for their comments on this paper (and Michele for her 'textese'); and thanks to Karl Maton for his comments, and also for editing and clarifying my recontextualisation of his ideas in section 4.
} 
absent from the model; but as Fig. 12 indicates (from Matthiessen ${ }^{6}$ 2007: 539), dialectal and codal variation has tended to be interpreted in relation to realisation and stratification rather than as a complementary hierarchy in its own right. The distinction between dialectal and codal variation is itself in fact predicated on the realisation hierarchy, following the traditional linguistic characterisation of dialects as different ways of saying the same thing, and coding orientation as meaning different things (Hasan 2005b).

Considered from a social perspective, the idea that dialects don't make meaning sits at odds with SFL's characteristic orientation to meaning. SFL's theory of metafunctions for example does not privilege ideational meaning over interpersonal and textual meaning (relegating the latter to pragmatics as in formal linguistic theory). And interpersonally speaking, both phonological and grammatical aspects of dialect variation certainly negotiate participation in speech communities, whose members regularly adjust their 'accents' in order to belong. In addition, SFL typically construes lexicogrammar as a meaning making stratum in its own right, and for those following Firth (e.g. 1957b), phonology and graphology make meaning as well. If meaning is made at all levels, then the need to differentiate dialectal from codal variation is obviated.

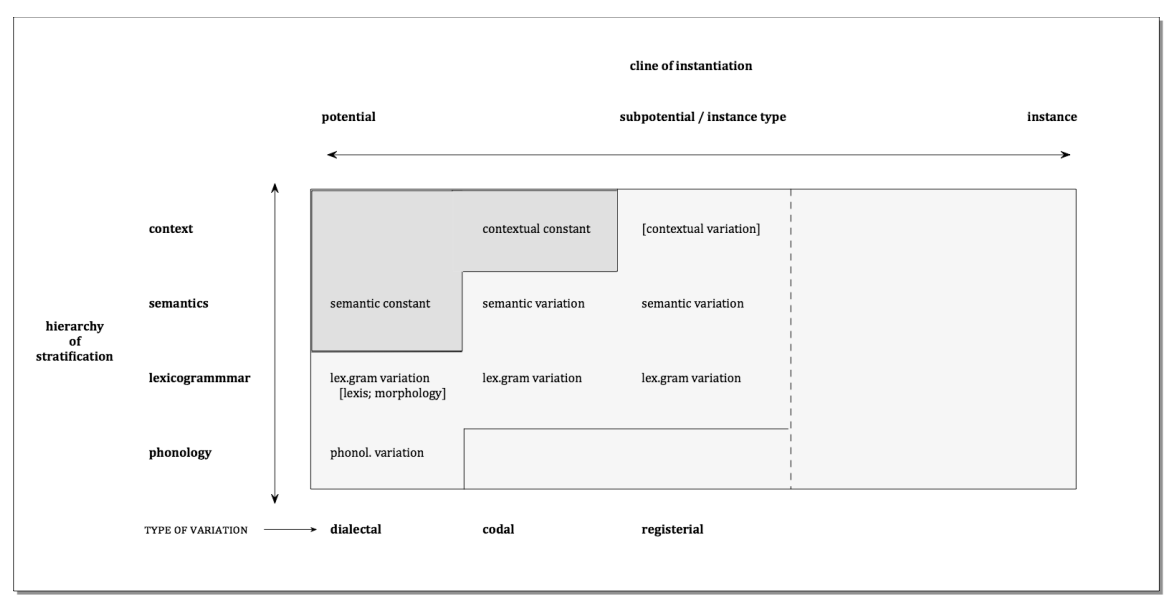

Figura 12: Dialect and code in relation to realisation \& instantiation (Matthiessen 2007: 539).

\footnotetext{
${ }^{6}$ I am however much indebted to Christian Matthiessen for drawing my attention to this term and theoretical dimension, at the meeting of the Australian Systemic Functional Linguistics Association in Adelaide in 2003.
} 
Accordingly, with a view to fostering research on users of language, I'm suggesting here that SFL develop a third hierarchy alongside realisation and instantiation, focusing on the allocation of the meaning potential of culture and its deployment for affiliation. ${ }^{8}$ The major dimensions of a model of this kind are outlined in Fig. 13 below in relation to genesis, taking into account logogensis - i.e. unfolding discourse at the instance end of the instantiation cline, ontogenesis - i.e. individual development at the repertoire end of the individuation cline, and phylogenesis - i.e. the evolutionary consequences of variation according to users (individuation) and uses (instantiation).

Progress developing models of allocation/affiliation is probably going to be as slow along this hierarchy as it has been for work on instantiation. For one thing, SFL's main tool for modelling meaning, the system network, is a synoptic one; it crystalises snapshots of semiotic valeur at particular points in time. The animated representations needed to interpret meaning unfolding through time, whether logogenetic, ontogenetic or phylogenetic are still under development. And then there is the difficulty of computing meaning, as noted above, once we move from parsing texts as bags of words to treating them as phonological, lexicogrammatical and discourse semantic patterns textures, through which meanings accumulate as texts unfold. The low level counting which technology currently affords is too shallow as far as meaning is concerned; and the rich manual analysis SFL currently enables is too limited as far as data is concerned. We're next to blind, groping towards a model of users and uses, in spite of, and in fact because of, our establishment of the richest realisational apparatus so far designed for.

\footnotetext{
${ }^{7}$ For related work in a comparable direction in critical discourse anlaysis and social semiotics, see Fairclough 2003 and van Leeuwen 2005 on style.

${ }^{8}$ Comparable concerns were modelled along the realisation hierarchy, as its deepest level of abstraction, as ideology, in Martin 1992.
} 


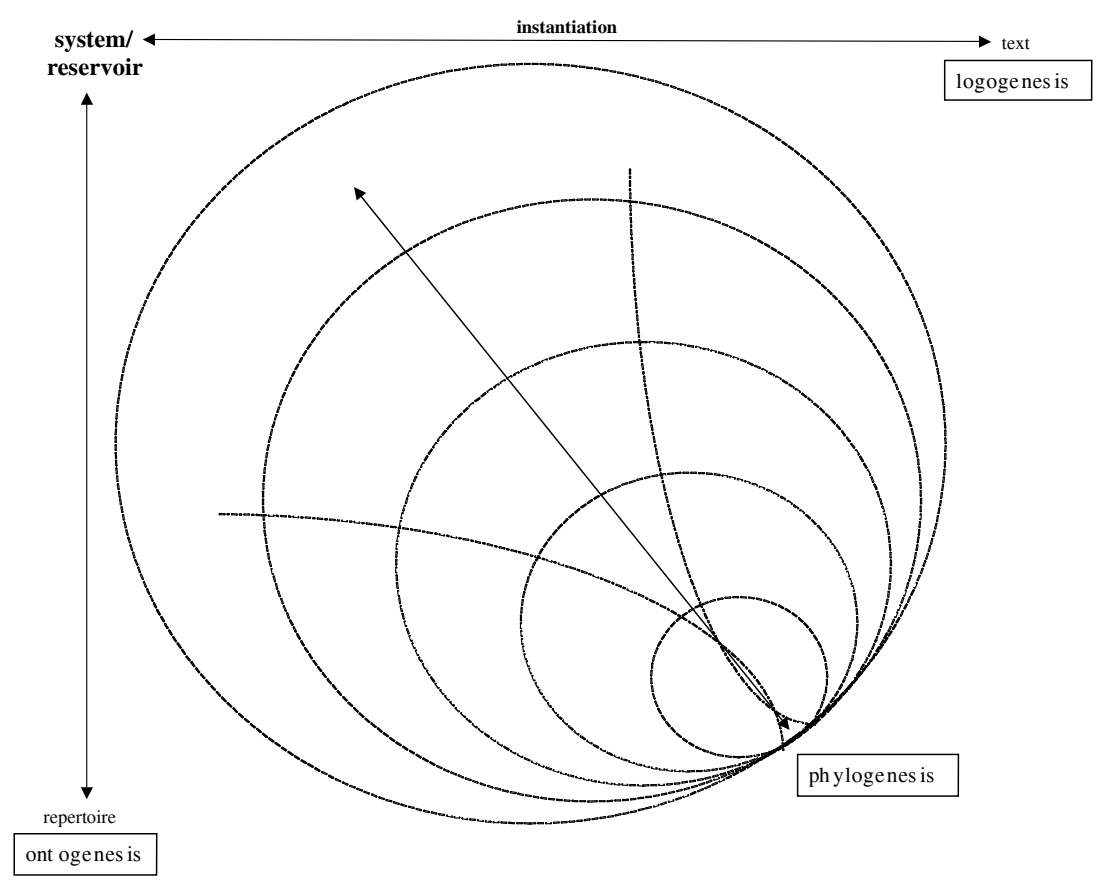

Figura 13: Realisation, instantiation and individuation in relation to genes

This is however no reason not to dream. And to make room for the generation of scholars ${ }^{9}$ that will take charge of enriching our understandings of instantiation and individuation in comparable terms.

Or as a suitably stylised teenage caricature might speak or write:

"Can't someone totally like just animate something like this, kind of, you know, whatever lol gtg =D!"

OMG sum1 anim8 dis! SFL EPIC FAIL! XD kthnxbai

9 For a glimpse of young scholars tackling individuation see Caldwell 2009, Knight 2009 and Tann 2009. 
Appendix: Continued negotiation of evaluation in mobile phone conference (text 3).

[And then when you went home that night was mum there?]

Yep.

[What did mum say when you got home?]

She was sleeping.

[Was Mum angry?]

Yeah.

[Did she get upset? What happened? Tell me what happened when mum found out what you did.]

[Did she cry?]

Lecture.

[Do you think you deserved the lecture? Why did you deserve the lecture?] Because I did something wrong.

[So if that was your phone, how would you feel if somebody stole your phone and then, you know, I decided I wanted to swap it with mine because mine was older. How would you feel about that?]

Pretty angry.

[So do you think you've learnt anything from this?]

(yep)

[What have you learnt?]

To not swap anything.

[Why would that be?]

[Because of what.]

Might be stolen

[At home did mum and dad- Did they ground you or did they put any restrictions on you? What happened?]

(I) just had to stay home. Come home straight from school.

Don't go anywhere.

[For how long?]

Till my court thing's finished.

[So you haven't been going out.]

[You've been staying at home with mum and dad.]

Yeah. 
[So that's not been very good has it.]

[So it's quite limiting in terms of what you can do?]

[Do you understand that that was the consequence of what you did?]

[Do you think that was reasonable, what mum and dad did grounding you?]

[Do you get pocket money off mum and dad?]

[Did they stop your pocket money?]

[No?]

[You got off light then, didn't you?]

[So you've apologised to Joseph already.]

Yeah.

[And your brothers, did they say anything to you?]

[No?]

[Do you think that mum and dad were disappointed in you?]

[Were you disappointed in yourself? Or Not? Or you don't care?]

Yeah.

[Yeah or you don't care?]

Disappointed in myself.

[OK, now what about the school situation.]

E-mail: jmartin@mail.usyd.edu.au

\section{REFERENCES}

Bednarek, M \& J R Martin [Eds.]. 2009. New Discourse on Language: functional perspectives on multimodality, identity and affiliation. London: Continuum.

Bernstein, B. 2000. Pedagogy, Symbolic Control and Identity: theory, research, critique. London: Taylor \& Francis. [Revised Edition].

Braithwaite, J. 1989. Crime, Shame and Reintegration. Cambridge: Cambridge University Press.

Caffarel, A, J. R. Martin, \& C. M. I. M. Matthiessen [Eds.]. 2004. Language Typology: a functional perspective. Amsterdam: Benjamins.

CALDwell, D. 2009. Meaking metre mean: identity and affiliation in the rap music of Kanye West. In Bednarek \& Martin. New Discourse on Language: functional perspectives on multimodality, identity and affiliation. London: Continuum. 
CAMERON, D. 2002. Styling the worker: gender and the commodification of language in the globalized service economy. Journal of Sociolinguistics 4.3. 323-347.

CRYstal, D. 2006. Language and the Internet. Cambridge; Cambridge University Press.

Christie, F. \& J. R. Martin 2007 Language, Knowledge and Pedagogy: functional linguistic and sociological perspectives. London: Continuum.

Faircough, N. 2003. Analysing Discourse: textual analysis for social research. London Routledge.

FirTh, J. R. 1957a. Personality and Language in Society. Papers in Linguistics 1934-1951. Oxford: Oxford University Press. 177-189.

FirTh, J. R. 1957b. Modes of meaning. Papers in Linguistics 1934-1951. London: Oxford University Press.190-215.

GeE, J. 1996. Social Linguistics and Literacies: ideology in discourses. [2nd Edition] Bristol, PA.: Taylor \& Francis.

GeE, J. 2005. An Introduction to Discourse Analysis. [2nd Edition] London: Routledge.

Halliday, M. A. K. 2005. Computing meanings: some reflections on part experience and present prospects. Computational and Quantitative Studies [Volume 6 in Collected Works of M A K Halliday Edited by Jonathon Webster]. London: Continuum. 239-267.

Halliday, M. A. K. 2008. Complementarities in Language. Beijing: The Commercial Press.

Halliday, M. A. K. \& W. S. Greaves. 2008. Intonation in the Grammar of English. London: Equinox.

Halliday, M. A. K. \& C. M. I. M. Matthiessen. 2004. An Introduction to Functional Grammar, $3^{\text {rd }}$ ed. London: Arnold.

Halliday, M. A. K., A. McIntosh \& P. Strevens. 1964. The Linguistic Sciences and Language Teaching. London: Longman.

Halliday, M. A. K. \& J. Webster [Eds.]. 2009. Continuum Companion to Systemic Functional Linguistics. London: Continuum.

Hasan, R. 1985. Linguistics, Language and Verbal Art. Geelong: Deakin University Press. [Republished by Oxford Unviersity Press 1989]

HASAN, R. 2005a. The ontogenesis of ideology: an interpretation of mother child talk. Language, Society and Consciousness. London: Equinox (The Collected Works of Ruqaiya Hasan edited by Jonathon Webster). 256274. 
Hasan, R. 2005b. Code, register and social dialect. Language, Society and Consciousness. London: Equinox (The Collected Works of Ruqaiya Hasan edited by Jonathon Webster). 160-193.

HASAN, R. 2005b. The ontogenesis of ideology: an interpretation of mother child talk. Language, Society and Consciousness. London: Equinox (The Collected Works of Ruqaiya Hasan edited by Jonathon Webster). 256-274.

Hasan, R. 2009. Semantic Variation: meaning in society and sociolinguistics. London: Equinox (The Collected Works of Ruqaiya Hasan, edited by Jonathon Webster).

Hasan, R., C. M. I. M. Matthiessen \& J. Webster [Eds.]. 2005. Continuing Discourse on Language: a functional perspective. Vol. 1. London: Equinox.

Hasan, R., C. M. I. M. Matthiessen \& J. Webster [Eds.]. 2007. Continuing Discourse on Language: a functional perspective. Vol. 2. London: Equinox.

Hood, S. in press Appraising Research: evaluation in academic writing. London: Palgrave.

KNIGHT, N. 2009. Wrinkling complexity: concepts of identity and affiliation in humour. in Bednarek \& Martin [Eds.]. 35-58.

MARTIN, J. R. 1992. English Text: system and structure. Amsterdam: Benjamins.

Martin, J. R. 1999. Modelling context: the crooked path of progress in contextual linguistics (Sydney SFL). M Ghadessy [Ed.] Text and Context in Functional Linguistics. Amsterdam: Benjamins (CILT Series IV). 25-61.

Martin, J. R. 2001. A context for genre: modelling social processes in functional linguistics. J Devilliers \& R Stainton [Eds.] Communication in Linguistics: papers in honour of Michael Gregory. Toronto: GREF (Theoria Series 10). 287-328.

Martin, J. R. 2006. Genre, ideology and intertextuality: a systemic functional perspective. Linguistics and the Human Sciences (Special Issue on Genre edited by J Bateman). 2.2. 275-298.

Martin, J.R. 2008a .Tenderness: realisation and instantiation in a Botswanan town. Odense Working Papers in Language and Communication (Special Issue of Papers from 34th International Systemic Functional Congress edited by Nina Nørgaard). 2008. 30-62.

MARTIN, J. R. 2008b. Innocence: realisation, instantiation and individuation in a Botswanan town. in N Knight \& A Mahboob [Ed.] Questioning Linguistics. Cambridge: Cambridge Scholars Publishing. 27-54.

Martin, J. R. 2009. Semantic variation: modelling system, text and affiliation in social semiosis. In Bednarek \& Martin. New Discourse on Language: functional perspectives on multimodality, identity and affiliation. London: Continuum. 
Martin, J. R. \& D. Rose. 2003. Working with Discourse: meaning beyond the clause.

London: Continuum [2nd Revised Edition 2007].

Martin, J. R. \& D. Rose. 2008. Genre Relations: mapping culture. London: Equinox.

Martin, J. R. \& P. R. R. White. 2005. The Language of Evaluation: appraisal in English. London: Palgrave.

Martin, J. R., M. Zappavigna \& P. Dwyer. 2007. Negotiating narrative: story structure and identity in youth justice conferencing. Linguistics and Human Communication. 3.2. 2007. 221-253.

Martin, J. R., M. Zappavigna \& P. Dwyer. 2009. Negotiating shame: exchange and genre structure in youth justice conferencing. in $\mathrm{C}$ Lipovsky \& A Mahboob [Eds.] Studies in Applied Linguistics and Language Learning. Newcastle upon Tyne: Cambridge Scholars Press. 41-73.

Martin, J. R., M. Zappavigna \& P. Dwyer. in press. Negotiating evaluation: story structure and appraisal in youth justice conferencing. i A Mahboob \& N Knight [Ed.] Appliable Linguistics: texts, contexts, and meanings. London: Continuum.

Maton, K. 2000. Recovering pedagogic discourse: a Bernsteinian approach to the sociology of educational knowledge. Linguistics $\&$ Education 11.1. 79-98.

Maton, K. 2007. Knowledge-knower structures in intellectual and educational fields. in Christie \& Martin. London: Continuum. 87-108.

Maton, K. 2009. Progress and canons in the arts and humanities: knowers and gazes. in K Maton \& R Moore, R [Eds.] Social Realism, Knowledge and the Sociology of Education: coalitions of the mind. London: Continuum. 154-178.

Maton, K. \& J. Muller, J. 2007. A sociology for the transmission of knowledges. In Christie, F. \& J. R. Martin 2007 Language, Knowledge and Pedagogy: functional linguistic and sociological perspectives. London: Continuum. 14-33.

Matthiessen, C. M. I. M. 2007. The 'architecture' of language according to systemic functional theory: developments since the 1970s. In R. Hasan, C M I M Matthiessen \& J Webster [Eds.] Continuing Discourse on Language: a functional perspective Vol. 2. 505-562.

Matthiessen, C. I. M. \& M. A. K. Halliday. 2009. Systemic Functional Grammar: a first step into the theory. Beijing: Higher Education Press. 
Moore, R. \& K. Maton. 2001. Founding the sociology of knowledge: Basil Bernstein, intellectual fields and the epistemic device. in A Morais, I Neves, B Davies \& H Daniels [Eds.] Towards a Sociology of Pedagogy: the contribution of Basil Bernstein to research. New York: Peter Lang. 153-182.

Moore, D. B. \& T. O'Connell. 1994. Family Conferencing in Wagga Wagga: A Communitarian Model of Justice In . Alder \& J Wundersitz [Eds.] Family Conferencing and Juvenile Justice: the way forward or misplaced optimism? Canberra: Australian Institute of Criminology.15-44.

Nathanson, D. L. 1997. From empathy to community'. The Annual of Psychoanalysis 25. 125-143.

Stenström, A., G. Anderson \& I. K. Hasund. 2002. Trends in Teen-age Talk: corpus compilation, analysis and findings. Amsterdam: Bejamins.

Stenström, A. \& A. M. JØ Rgensen. 2009. Youngspeak in a Multilingual Perspective. Amsterdam: Benjamins.

TANN, K. 2009. Imagining communities: a multifunctional approach to identity management in texts. In Bednarek \& Martin. New Discourse on Language: functional perspectives on multimodality, identity and affiliation. London: Continuum.

ThurLow, C. 2007. Fabricating youth: new-media discourse and the technologization of young people. In S Johnson \& A Ensslin [Eds.] Language in the Media: representations, identities, ideologies. London: Continuum. 213-233.

van Leeuwen, T. 2005. Introducing Social Semiotics. London: Routledge.

Williams, G. 2005. Semantic variation. in Hasan et al. 457-480.

Webster, J [Ed.]. 2008. Meaning in Context: strategies for implementing intelligent applications of language studies. London: Continuum.

Zappavigna, M., P. Dwyer, P., \& J. R . Martin. 2008. "Just like sort of guilty kind of": The rhetoric of tempered admission in Youth Justice Conferencing. M Zappavigna [Ed.] ASFLA 2007 Proceedings. Australian Systemic Functional Linguistics Association. http://www.asfla.org.au/ 2008/07/31/the-rhetoric-of-tempered-admission-in-youth-justiceconferencing/

Zappavigna, M., C. CLeirigh, P. Dwyer \& J. R. Martin. 2009. Multimodal Coupling in Youth Justice Conferencing. In Bednarek, M \& J R Martin [Eds.]. 2009. New Discourse on Language: functional perspectives on multimodality, identity and affiliation. London: Continuum. 219-236. 